\title{
Combinação de águas doce e salobra para produção de alface hidropônica
}

\author{
$\overline{\text { Tales M. Soares }^{1} \text {, Sergio N. Duarte }}{ }^{2}$, Ênio F. F. Silva ${ }^{3} \&$ Cristiano A. Jorge $^{2}$
}

RESUMO

Plantas de alface crespa cv. Verônica foram cultivadas em condição hidropônica objetivando-se avaliar dois tipos de emprego combinado de águas doce e salobras, quais sejam: usar as águas salobras para preparar a solução nutritiva (SN) e a água doce para repor a evapotranspiração da cultura (ETC) (Experimento I) e usar a água doce para preparar a SN e as salobras para a reposição da ETc (Experimento II). U ma estrutura de pesquisa com 40 parcelas que simulam a técnica do fluxo laminar de nutrientes (NFT) foi construída. 0 s níveis de salinidade da água testados foram: 0,585; 1,17; 1,755; 2,925 e 4,095 g L-1 de $\mathrm{NaCl}$. A salinidade diminuiu a produtividade da alface (massa de matéria fresca da parte aérea) em 10,9 e 3,91\% para cada acréscimo unitário na salinidade da água ( $\mathrm{g} \mathrm{L}^{-1} \mathrm{de} \mathrm{NaCl}$ ), considerando-se os Experimentos I e II, respectivamente. De acordo com os resultados obtidos com os dois tipos de combinação de águas doce e salobras, o uso de águas salobras para repor a ETc pode aumentar a produtividade da alface em comparação com o uso dessas águas para preparar a SN.

Palavras-chave: salinidade, cultivo sem solo, hortaliças, águas subterrâneas, irrigação

\section{Combination of fresh and brackish waters for hydroponic lettuce production}

\begin{abstract}
Plants of crisphead lettuce cv. Verônica were grown under hydroponic conditions aiming to evaluate two types of combination of brackish and fresh waters: using the brackish waters to prepare nutrient solution (N S) and fresh water to replace the evapotranspiration loss (ETC) (Experiment I) and using the fresh water to prepare NS and the brackish waters to replace the ETC loss (Experiment II). A research structure was built up with 40 experimental units which simulated the nutrient film technique (NFT). The levels of water salinity were $0.585 ; 1.17 ; 1.755 ; 2.925$ and $4.095 \mathrm{~g} \mathrm{~L}^{-1} \mathrm{~N} \mathrm{aCl}$. The lettuce yield (fresh shoot matter) decreased 10.9 and $3.91 \%$ for each unit increase in water salinity $\left(\mathrm{g} \mathrm{L}^{-1} \mathrm{NaCl}\right.$ ) in Experiments I and II, respectively. According to results obtained with the two types of combination of fresh and brackish waters, the use of brackish waters to replace ETc loss may increase the lettuce yield in comparison to using these waters to prepare the NS.
\end{abstract}

Key words: salinity, soilless cultivation, vegetables, groundwaters, irrigation 


\section{INTRODUÇÃO}

A escassez de águas superficiais no Semiárido é um reconhecido fator limitante ao desenvolvimento da região. Uma alternativa que poderia reduzir esta carência são as águas subterrâneas (Andrade Júnior et al., 2006; Medeiros et al., 2003), que podem ser menos onerosas e ter melhor qualidade sanitária. Entretanto, devido à geologia regional, com predominância do embasamento cristalino, em associação com o balanço hídrico negativo, é recorrente se obter águas salobras no subsolo da referida região. Por este motivo, inúmeros poços perfurados no Semiárido estão abandonados ou em sub-utilização (Costa et al., 2006; Zoby \& Oliveira, 2005).

Nos últimos anos, algumas pesquisas têm procurado avaliar a viabilidade de aproveitamento de águas salobras em cultivos hidropônicos (Soares et al., 2007; Paulus, 2008; Santos, 2009; Amorim et al., 2005). A hipótese básica na maioria desses estudos é que, na hidroponia, a resposta das plantas em condições salinas é melhor que no cultivo convencional baseado no solo, visto que na hidroponia pode não existir o potencial mátrico, que é uma das causas da diminuição da energia livre da água no solo (Soares et al., 2007). Enquanto a tensão da água no solo aumenta entre um evento de irrigação e outro, o que se percebe no monitoramento com tensiômetros (Santos \& Pereira, 2004), na hidroponia (em água) a tensão tende à nulidade, pois o meio é saturado com água (forças de adesão e retenção não se estabelecem) e neste cultivo os eventos de irrigação são repetíveis em alta frequência. Na hidroponia do tipo NFT (nutrient technique film), por exemplo, é usual que a irrigação se processe de 15 em 15 min (Zanella et al., 2008).

Considerando a perspectiva de uso de águas salobras em hidroponia, sua combinação com água doce poderia ser útil para incrementar a produtividade das culturas ou, ainda, a área cultivada. As combinações de uso poderiam passar pelas misturas físicas desses tipos de água, ou pelo seu uso em fases específicas do ciclo. Outra maneira de combinação seria usar águas salobras apenas no preparo da solução nutritiva ou apenas na reposição do volume evapotranspirado. No primeiro caso, a salinidade poderia ser mantida relativamente constante durante o cultivo, enquanto a salinização seria crescente no segundo caso.

Estudos envolvendo tolerância das plantas aos sais geralmente são conduzidos mantendo-se constantes os níveis de salinidade. Mais do que preferência dos pesquisadores, isto se deve às metodologias primordialmente empregadas em cultivos em solo. Ayers \& Westcot (1999) atestam como tal procedimento faz jus à sua ampla aceitação: como o manejo das águas salobras diz respeito ao equilíbrio dos íons do meio, mediante o uso da fração de lixiviação, é natural que se busque repetir na pesquisa tal equilíbrio; daí se justificar a busca dos níveis constantes nos estudos de tolerância (Medeiros et al., 2009; Eloi et al., 2007).

Por outro lado, em muitas situações de campo, testemunha-se o aumento da salinidade ao longo do ciclo. Esta salinização pode ser descontrolada, marcando um dos principais problemas da agricultura irrigada mundial (Ayers \& Westcot, 1999), como se reproduz nas áreas abandonadas no Nordeste do Brasil (Barros et al., 2004; Andrade et al., 2004; Nunes et al., 2000; Lopes et al., 2008). Mas, também, pode ser controlável, como verificado no Estado do Rio Grande do Norte, em que a evolução da salinização é corrigida após os períodos de chuva e onde já se reportam anos de sucesso na produção de melão irrigado com águas salobras. Outro exemplo seria a utilização de águas salobras na hidroponia do tipo circulante, como a NFT, que associa irrigação e drenagem na mesma estrutura, permitindo se destinar apropriadamente o efluente residual (solução nutritiva envelhecida e salinizada) ao final do ciclo (Soares et al., 2007; Santos, 2009).

Tratando do aproveitamento de águas salobras em hidroponia, seu uso exclusivamente para a reposição da evapotranspiração pode ser menos prejudicial às culturas de ciclo curto do que o seu emprego apenas para o preparo da solução nutritiva, pois a salinização gradual seria menos danosa do que a salinidade constante, mas estabelecida desde o início do ciclo.

A partir da análise de dois experimentos conduzidos em uma mesma estrutura de hidroponia NFT, mas em épocas diferentes, procurou-se averiguar qual procedimento é mais vantajoso na produção de alface crespa cv. Verônica: usar água doce para o preparo da solução nutritiva e água salobra para reposição da evapotranspiração ou usar água doce para repor a evapotranspiração e água salobra para o preparo da solução nutritiva.

\section{MATERIAL E MÉTODOS}

Dois experimentos foram conduzidos no Departamento de Engenharia Rural da Escola Superior de Agricultura 'Luiz de Queiroz' ESALQ-USP, na cidade de Piracicaba, SP, em uma casa de vegetação do tipo arco simples com 17,8 m de comprimento, 7,1 $\mathrm{m}$ de largura, pé-direito de $3 \mathrm{~m}$, altura do arco de 1,35 m e orientação leste-oeste $\left(22^{\circ} 42^{\prime} 89,4^{\prime \prime}\right.$ latitude Sul, $47^{\circ} 37^{\prime}$ 46,2" de longitude Oeste e $540 \mathrm{~m}$ de altitude). Esses experimentos não foram estabelecidos concomitantemente, mas, tanto no Experimento I (31/12/2006 a 25/01/2007) quanto no Experimento II (16/04/2007 a 11/05/2007) foi empregada a mesma estrutura de pesquisa.

$\mathrm{Na}$ Figura 1 se encontram a variação da temperatura do ar, medida a $1 \mathrm{~m}$ de altura, e a variação da temperatura da solução nutritiva, medida no interior do reservatório. Em ambos os experimentos foram verificadas temperaturas máximas acima do nível crítico para a alface (Rodrigues, 2002), tanto na atmosfera da casa de vegetação $\left(>30^{\circ} \mathrm{C}\right)$ quanto na solução nutritiva $\left(>30^{\circ} \mathrm{C}\right)$. No Experimento II, as temperaturas foram mais variáveis, como resposta à transição para a estação fria

Avaliou-se, em ambos os experimentos, a produção de alface crespa cultivar 'Verônica'. As mudas foram produzidas em espuma fenólica $(2,0 \times 2,5 \times 3,0 \mathrm{~cm})$ em berçário dotado de um sistema hidropônico NFT, em condições não salinas. Com cinco folhas definitivas, as mudas foram transplantadas aos 30 dias após a semeadura (DAS) para o Experimento I e aos 34 DAS para o Experimento II. Em ambos os casos as plantas foram colhidas com 25 dias após o transplantio (DAT). Os 


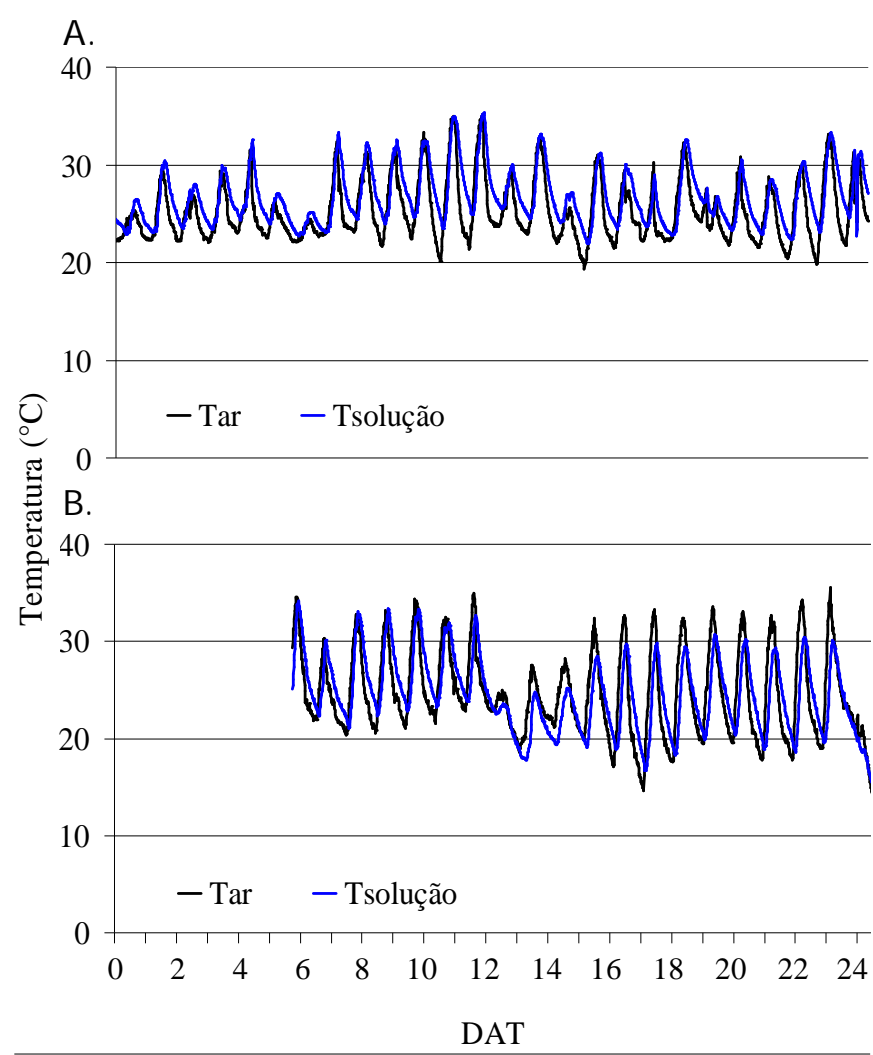

Figura 1. Temperatura do ar medida a $1 \mathrm{~m}$ de altura $\left(\mathrm{T}_{\text {rr }}\right)$ e temperatura da solução nutritiva $\left(\mathrm{T}_{\text {solução }}\right)$ ao longo dos Experimento I (A) e II (B)

tratamentos foram aplicados imediatamente após o transplantio.

Utilizou-se uma estrutura hidropônica composta de 40 unidades experimentais. Cada parcela simula um sistema independente de hidroponia NFT, sendo composta por um perfil hidropônico ( $3 \mathrm{~m}$ de comprimento), uma eletrobomba, um reservatório de solução nutritiva $(45 \mathrm{~L})$ e um tanque de abastecimento automático (20 L) (com torneira-bóia). A descrição detalhada dessa estrutura é apresentada por Soares et al. (2009).

Foram estudados dois tipos de uso combinado de águas doce e salobras no cultivo da alface. No Experimento I, foram utilizadas águas salobras no preparo da solução nutritiva e água doce para repor o volume evapotranspirado; já no Experimento II, as águas salobras foram usadas para a reposição da evapotranspiração, sendo a água doce empregada para o preparo da solução nutritiva.

As perdas por evapotranspiração eram instantaneamente repostas ao sistema mediante o tanque de abastecimento automático. A água fornecida não era fertilizada e sua salinidade era dependente do tratamento. Durante os experimentos não se trocou a solução nutritiva nem se repôs os nutrientes consumidos pelas plantas. Este procedimento foi adotado pela alta disponibilidade volumétrica de solução nutritiva por planta, qual seja, 5,3 L, ressalvando-se que o recomendado na literatura especializada é um volume em torno de $1 \mathrm{~L}$ por planta.

Cada parcela correspondia a um perfil hidropônico com oito plantas, mas dessas apenas as plantas centrais foram consideradas úteis. Em ambos os experimentos, se adotou a alea- torização dos tratamentos em blocos, cujo número era coincidente com o de repetições: 4 repetições no Experimento I e 6 repetições no Experimento II.

Para a produção das águas salobras, adicionou-se $\mathrm{NaCl}$ à água do abastecimento local (da 'Estação de Tratamento de Água' do campus da ESALQ). As quantidades de 0,$585 ; 1,17$, 1,$755 ; 2,925$ e $4,095 \mathrm{~g} \mathrm{~L}^{-1}$ de $\mathrm{NaCl}$ são respectivas aos tratamentos T1, T2, T3, T5 e T7 do Experimento I. Esses tratamentos correspondem aos tratamentos W1, W2, W3, W5 e W7 do Experimento II (Tabela 1).

Tabela 1. Concentrações de $\mathrm{NaCl}, \mathrm{Cl}^{-}$e $\mathrm{Na}^{+}$e salinidades iniciais da solução nutritiva (CEsol) nos diferentes tratamentos dos Experimentos I e II

\begin{tabular}{|c|c|c|c|c|c|c|}
\hline \multirow{2}{*}{$\begin{array}{l}\mathrm{NaCl} \\
\left(\mathrm{g} \mathrm{L}^{-1}\right)\end{array}$} & \multirow{2}{*}{\multicolumn{2}{|c|}{$\frac{\mathrm{Cl}^{-} \mathrm{Na}^{+}}{(\text {mmolc L-1) }}$}} & \multicolumn{2}{|r|}{ Exp. I } & \multicolumn{2}{|r|}{ Exp. II } \\
\hline & & & Trat* & CEsol** (dS $\left.\mathrm{m}^{-1}\right)$ & Trat* & CEsol** $^{*}\left(\mathrm{dS}^{-1}\right)$ \\
\hline 0 & 0 & 0 & TO & 2,09 & Wo & 2,24 \\
\hline 0,585 & 10 & 10 & T1 & 3,03 & W1 & 2,24 \\
\hline 1,170 & 20 & 20 & $\mathrm{~T} 2$ & 4,01 & W2 & 2,24 \\
\hline 1,755 & 30 & 30 & T3 & 4,97 & W3 & 2,24 \\
\hline 2,925 & 50 & 50 & T5 & 6,86 & W5 & 2,24 \\
\hline 4,095 & 70 & 70 & $\mathrm{T7}$ & 8,67 & W7 & 2,24 \\
\hline
\end{tabular}

*trat: tratamento; **Valores de CEsol foram dependentes da sazonalidade da qualidade da água disponível no abastecimento local. A água tratada no Campus da ESALQ segue os padrões de potabilidade estabelecidos pela Portaria 518/04 de 25/03/2004 do Ministério da Saúde

Os tratamentos T0 e W0 são equivalentes entre si, considerados controle (sem adição de $\mathrm{NaCl}$ ) dos Experimento I e II, respectivamente, e possuem salinidade dependente apenas dos íons da água do abastecimento local e dos fertilizantes empregados na formulação da solução nutritiva recomendada por Furlani et al. (1999).

A evolução da salinidade nos tratamentos em ambos os experimentos foi acompanhada com medições periódicas (intervalos não regulares) da condutividade elétrica da solução nutritiva (CEsol). A redução da salinidade e a média ponderada da salinidade no tempo, em termos absolutos e relativos à condição inicial, foram determinadas para cada tratamento de cada experimento.

Aos 25 DAT, processou-se a colheita: as plantas foram cortadas na região do colo e a parte aérea imediatamente pesada em balança de precisão para obtenção da massa de matéria fresca da parte aérea (MFPA); a seguir, mediu-se o diâmetro da parte aérea (DPA) com o auxílio de uma trena e se contou o número de folhas (NF) com comprimento maior que $10 \mathrm{~cm}$. As plantas foram submetidas, individualmente, à análise visual de sintomas. Após secagem em estufa com circulação forçada, obteve-se a massa de matéria seca da parte aérea (MSPA); calculou-se o teor de água nos tecidos da parte aérea das plantas de alface.

O consumo hídrico também foi analisado mediante leituras diárias nos reservatórios de abastecimento automático: foram avaliados os períodos do $2^{\circ}$ ao $25^{\circ}$ DAT no Experimento I e do $5^{\circ}$ ao $25^{\circ}$ DAT no Experimento II, empregando-se a Eq. 1.

$$
\mathrm{V}_{\mathrm{ETC}}=\frac{(\mathrm{Lf}-\mathrm{Li}) \times \pi \times \mathrm{D}^{2}}{4 \times \mathrm{n} \times \Delta \mathrm{T}} \times 10^{6}
$$


em que:

$\mathrm{V}_{\text {ETC }}$ - volume evapotranspirado, mL planta ${ }^{-1} \mathrm{dia}^{-1}$

Lf - leitura final do nível da água no depósito de abastecimento automático, $\mathrm{m}$

$\mathrm{Li}$ - leitura inicial do nível da água no depósito de abastecimento automático, $\mathrm{m}$

D - diâmetro interno do depósito de abastecimento automático, $\mathrm{m}$

"T - intervalo de tempo entre as leituras, dias $\mathrm{n}$ - número de plantas no perfil no intervalo de tempo "T

Por se tratar de dados quantitativos, os resultados foram submetidos às análises de variância e de regressão, com processamento no software SAS. Os modelos de regressão foram selecionados com base na significância de seus termos e no valor do coeficiente de determinação. Para funções de primeiro grau, a razão a/b entre os coeficientes angular (a) e linear (b) foi empregada para se estimar as reduções percentuais nas variáveis analisadas por acréscimo unitário da salinidade da água.

Como os experimentos não foram conduzidos nem colhidos nas mesmas condições ambientais, restringir-se-á a análise dos dados entre os tratamentos apenas à base dos valores relativos (a cada controle). As análises estatísticas apresentadas dizem respeito tão somente aos dados observados dentro de cada experimento.

\section{RESULTADOS E DISCUSSÃO}

No Experimento I, as diferenças entre as CEsol dos tratamentos se mantiveram relativamente constantes do início ao final do ciclo, comportamento este esperado em função da reposição da evapotranspiração com água doce, o que tende a conservar a concentração dos sais. O decréscimo absoluto (S) da CEsol observado dentro de cada tratamento pode ser explicado pela não reposição dos nutrientes consumidos ao longo do tempo (Tabela 2 e 3). Esta redução foi aproximadamente a mesma para todos os tratamentos, estando contida no intervalo de 0,70 a $0,95 \mathrm{dS} \mathrm{m} \mathrm{m}^{-1}$. Obviamente, para essas magnitudes equivalentes na diminuição absoluta da CEsol, os tratamentos mais salinos sofreram menor variação percentual (D) ao longo do tempo (Tabela 3).

Em consequência da redução mais acentuada da CEsol apenas ao final do ciclo, a salinidade ponderada no tempo foi ainda menos diferente da CEsol inicial, em todos os tratamen-

Tabela 2. Salinidade da solução nutritiva (CEsol) e sua média ponderada no tempo nos diferentes tratamentos ao longo do Experimento I

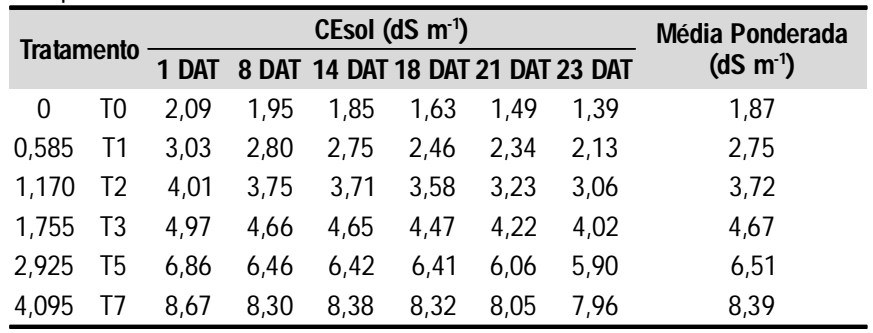

tos do Experimento I; dessa forma, a diferença percentual da salinidade ponderada em relação à salinidade inicial $(\mathrm{Dp})$ foi de $10,6 \%$ para o tratamento controle e de $3,2 \%$ para o $\mathrm{T} 7$, demonstrando também, obviamente, a mesma tendência de diminuição da variação com o aumento da salinidade característica do tratamento (Tabela 3 ).

Já no Experimento II, e em função do emprego das águas salobras na reposição da evapotranspiração da alface cv. Verônica, a salinidade foi crescente para todos os tratamentos salinos ao longo do tempo, o que se refletiu nas elevadas variações absolutas e percentuais apresentadas na Tabela 3. Apenas na reposição com a água não salobra (W0) houve redução da salinidade da solução nutritiva em decorrência do consumo de nutrientes, que deve ser superior ao baixo aporte de sais dissolvidos nessa água (Tabela 4). Esses mesmos comportamentos foram observados em hidroponia com sílica em vasos (Soares et al., 2007) quando também se usou água doce no preparo da solução nutritiva, reservando as águas salobras para a reposição da evapotranspiração; entretanto, a magnitude da salinização foi menor no Experimento II em relação ao trabalho de Soares et al. (2007), mesmo sendo consumida mais água no presente trabalho, o que pode ser atribuído principalmente à disponibilidade de solução nutritiva por planta.

Enquanto Soares et al. (2007) disponibilizaram 1,1 L por planta, no Experimento II foram disponibilizados cerca de 5,3 L por planta; desta forma, enquanto a água de maior salinidade no trabalho dos outros autores $\left(\mathrm{CEa}=3,93 \mathrm{dS} \mathrm{m}^{-1}\right)$ elevou a CEsol de 1,95 para $8,13 \mathrm{dS} \mathrm{m}^{-1}$ em 28 dias, no Experimento II, a água de maior salinidade $\left(7,46 \mathrm{dS} \mathrm{m}^{-1}\right)$ elevou a CEsol de 2,24 para apenas 7,07 $\mathrm{dS} \mathrm{m}^{-1}$ em 25 dias (Tabela 4).

A disponibilização de 5,3 L de solução nutritiva por planta no presente trabalho não está de acordo com a recomendação para produção comercial de alface, qual seja, 1 a 2 L por planta (Furlani et al., 1999). Por outro lado, pode ser mais adequada ao emprego de águas salobras, o que deveria ser testado em pesquisas futuras sob a hipótese de que, quanto maior a disponibilidade de solução nutritiva menor é o efeito da salinização, já que a incorporação de sais é relativamente maior para menores disponibilidades.

As taxas de salinização diária entre períodos consecutivos ao longo do ciclo no Experimento II são bem visualizadas para os tratamentos mais salinos (W3, W5 e W7) (Figura 2). Constatou-se que, nesses tratamentos, a salinização aumentou na primeira metade do ciclo e depois tendeu a diminuir, comportamento semelhante ao do consumo de água (Figura 3), o que se compreende pelo aporte de íons em proporcionalidade ao volume de água aplicado. Evidentemente, os tratamentos menos salinos (W0 e W1) não poderiam apresentar o mesmo padrão de resposta de taxas de salinização entre períodos consecutivos (Figura 2). Nesses tratamentos, menos sais devem ser incorporados, a despeito do maior consumo hídrico, pois suas concentrações são mais baixas nas águas de reposição, havendo ainda a possibilidade de uma extração maior de íons (nutrientes) em resposta ao crescimento mais destacado (como será mostrado a seguir) das plantas. Esses fatores podem explicar as oscilações, inclusive os valores negativos de salinização, apresentados na Figura 2. 
Tabela 3. Variação absoluta (S) e percentual (D) da CEsol do início ao final do ciclo e diferença absoluta (Sp) e percentual (Dp) da CEsol ponderada em relação à CEsol inicial

\begin{tabular}{|c|c|c|c|c|c|c|c|c|c|}
\hline \multirow{2}{*}{ Tratamento } & \multicolumn{4}{|c|}{ Experimento I } & \multirow{2}{*}{ Tratamento } & \multicolumn{4}{|c|}{ Experimento II } \\
\hline & $S\left(d S ~ m^{-1}\right)$ & $\mathrm{D}(\%)$ & $S p\left(d S m^{-1}\right)$ & Dp (\%) & & $S\left(\mathrm{dS} \mathrm{m}^{-1}\right)$ & $\mathrm{D}(\%)$ & $S p\left(d S m^{-1}\right)$ & $\mathrm{Dp}(\%)$ \\
\hline TO & $-0,70$ & $-33,4$ & $-0,22$ & $-10,6$ & Wo & $-0,84$ & $-37,6$ & $-0,59$ & $-29,6$ \\
\hline $\mathrm{T} 1$ & $-0,90$ & $-29,7$ & $-0,28$ & $-9,1$ & W1 & $+0,06$ & $+2,9$ & $+0,01$ & $+0,6$ \\
\hline $\mathrm{T} 2$ & $-0,95$ & $-23,6$ & $-0,29$ & $-7,2$ & W2 & $+0,83$ & $+37,0$ & $+0,51$ & $+19,7$ \\
\hline T3 & $-0,95$ & $-19,1$ & $-0,31$ & $-6,2$ & W3 & $+1,78$ & $+79,4$ & $+1,12$ & $+38,7$ \\
\hline $\mathrm{T5}$ & $-0,95$ & $-13,9$ & $-0,34$ & $-5,0$ & W7 & $+3,48$ & $+155,0$ & $+2,18$ & $+61,7$ \\
\hline $\mathrm{T7}$ & $-0,71$ & $-8,2$ & $-0,28$ & $-3,2$ & wo & $+4,82$ & $+214,8$ & $+3,04$ & $+75,4$ \\
\hline
\end{tabular}

Tabela 4. Salinidade da solução nutritiva (CEsol) e sua média ponderada no tempo nos diferentes tratamentos ao longo do Experimento II

\begin{tabular}{|c|c|c|c|c|c|c|c|c|c|c|}
\hline \multirow{2}{*}{$\mathrm{NaCl}\left(\mathrm{g} \mathrm{L}^{-1}\right)$} & \multirow{2}{*}{ Tratamento } & \multicolumn{8}{|c|}{ CEsol (dS $\mathrm{m}^{-1}$ ) } & \multirow{2}{*}{$\begin{array}{c}\text { Média } \\
\text { Ponderada } \\
\left(\mathrm{dS} \mathrm{m}^{-1}\right)\end{array}$} \\
\hline & & O DAT & 5 DAT & 8 DAT & 13 DAT & 15 DAT & 18 DAT & 22 DAT & 25 DAT & \\
\hline 0 & Wo & 2,24 & 2,15 & 2,19 & 2,04 & 1,98 & 1,84 & 1,47 & 1,40 & 1,99 \\
\hline 0,585 & W1 & 2,24 & 2,23 & 2,31 & 2,30 & 2,33 & 2,38 & 2,25 & 2,31 & 2,30 \\
\hline 1,170 & W2 & 2,24 & 2,33 & 2,43 & 2,55 & 2,65 & 2,83 & 2,93 & 3,07 & 2,57 \\
\hline 1,755 & W3 & 2,24 & 2,44 & 2,55 & 2,84 & 3,08 & 3,41 & 3,79 & 4,03 & 2,90 \\
\hline 2,925 & W5 & 2,24 & 2,70 & 2,92 & 3,44 & 3,85 & 4,44 & 5,24 & 5,72 & 3,54 \\
\hline 4,095 & W7 & 2,24 & 2,86 & 3,16 & 3,89 & 4,41 & 5,30 & 6,43 & 7,07 & 4,03 \\
\hline
\end{tabular}

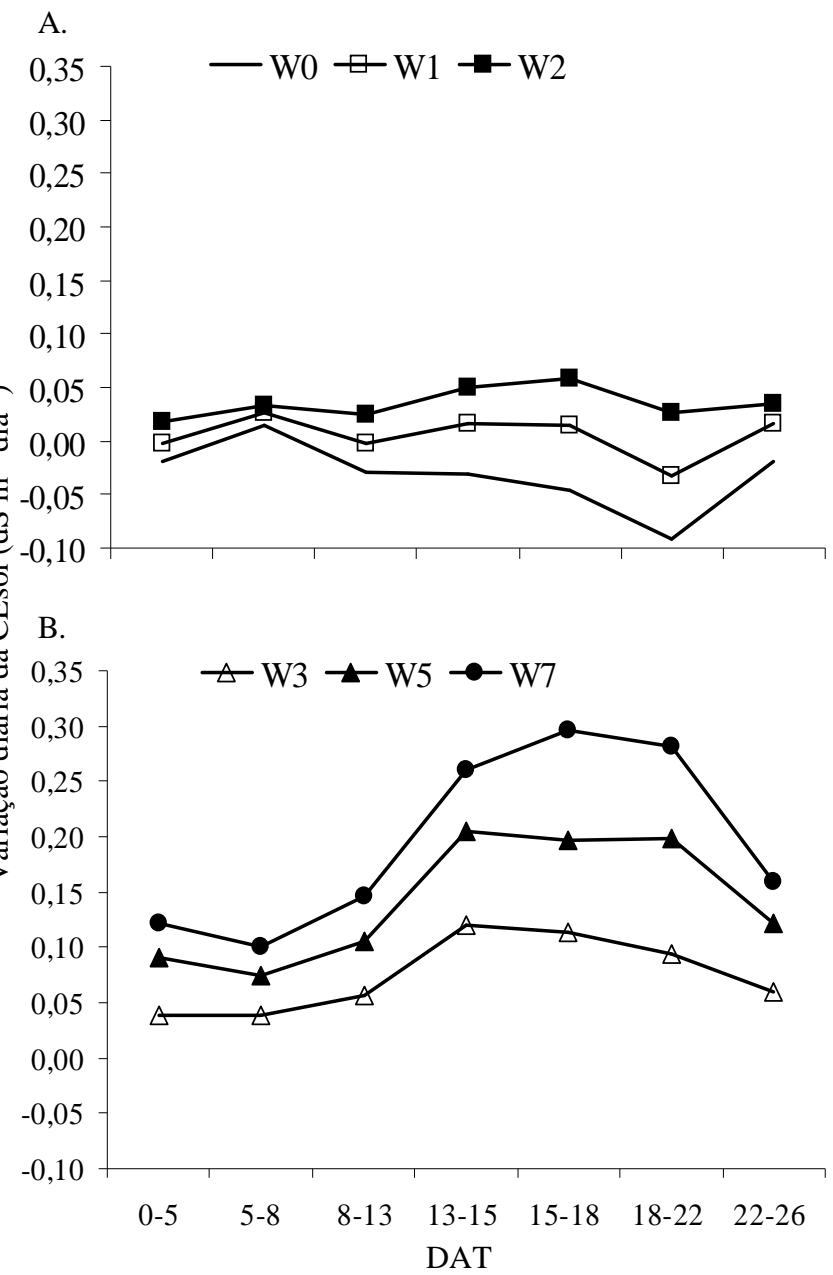

Figura 2. Variação diária da CEsol em sete períodos ao longo do ciclo da alface, conforme os tratamentos menos salinos (A) e mais salinos (B) do Experimento II

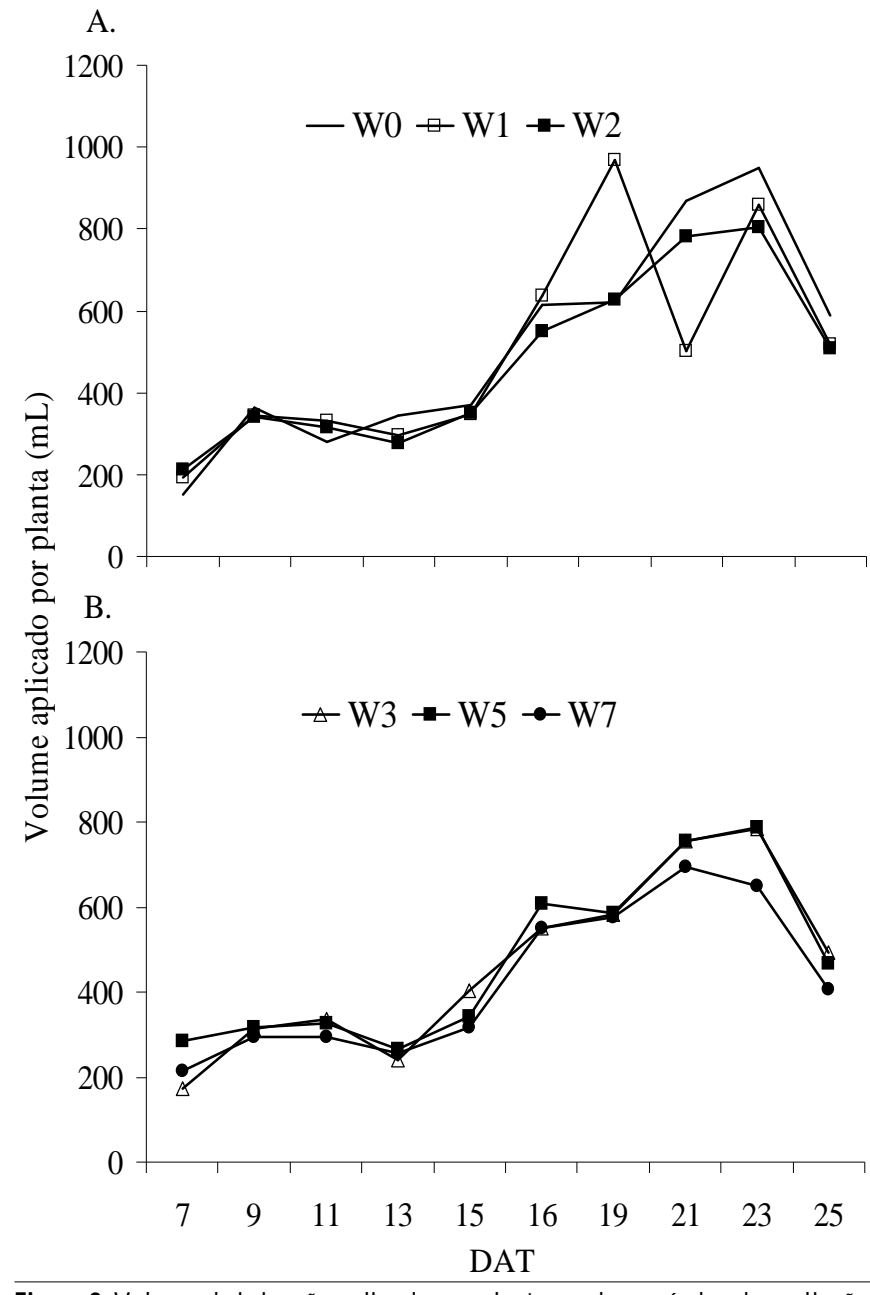

Figura 3. Volume de irrigação aplicado por planta em dez períodos de avaliação ao longo do Experimento II (6 aos 25 DAT) para os tratamentos menos salinos (A) e mais salinos (B) 
Em base de volume de água aplicado por planta, a maior salinização no Experimento II foi estimada em 1,14 dS m $\mathrm{m}^{-1} \mathrm{~L}^{-1}$ contra 1,93 dS m $\mathrm{d}^{-1} \mathrm{~L}^{-1}$ no trabalho de Soares et al. (2007), sendo expressivamente menos intensa, uma vez que se trata do contraste de uma água salobra de $7,46 \mathrm{dS} \mathrm{m}^{-1}$ com outra de 3,93 $\mathrm{dS} \mathrm{m}^{-1}$. A despeito de serem conduzidos em hidroponia e empregarem águas salobras apenas para repor a ETc, essas duas investigações trazem resultados bem distintos quanto à salinização, o que deve ser respeitado antes de recomendações generalistas para o uso combinado de águas salobras.

Foi interessante observar que a salinidade final dos tratamentos no Experimento II foi muito semelhante à salinidade final do Experimento I (Tabela 2, Tabela 4), ou seja, a salinização gradual no Experimento II e a moderada 'dessalinização' (extração de íons pela nutrição da alface) em ambos os experimentos tenderam a confluir os níveis finais de salinidade para os mesmos patamares. Respeitando-se, entretanto, as médias ponderadas no tempo para ambos os casos, tem-se que registrar que no Experimento II a salinidade foi menor para cada nível inicial de $\mathrm{NaCl}$. Por outro lado, para os agricultores interessados em aproveitar o efluente hidropônico em um segundo cultivo, não seria grande vantagem empregar o uso combinado do Experimento II, ao menos do ponto de vista osmótico. Diferenças nutricionais precisariam ser estudadas entre os efluentes de cada tipo de uso combinado para se permitir conclusões mais generalistas.

Verificou-se, no Experimento II, diminuição linear do consumo hídrico em função do aumento da salinidade da água de reposição (Figura 4). Em relação à água de baixa salinidade (controle), no Experimento II foi calculada uma redução de $15,1 \%$ no consumo hídrico para a água de $7,29 \mathrm{dS} \mathrm{m}^{-1}$. Semelhante redução percentual foi encontrada por Soares et al. (2007) (17,9\%), mas para uma água de 3,93 $\mathrm{dS} \mathrm{m}^{-1}$ e que tinha, na sua composição, $\mathrm{CaCl}_{2}$, além do $\mathrm{NaCl}$ (1:1 base peso).

Das equações lineares apresentadas na Figura 4, calculase um decréscimo no consumo hídrico de $9,22 \%$ para cada $g$ $\mathrm{L}^{-1}$ de $\mathrm{NaCl}$, no Experimento I. Para o Experimento II, por sua vez, a redução foi de 3,69\% para cada $\mathrm{g} \mathrm{L}^{-1} \mathrm{de} \mathrm{NaCl}$; este resultado demonstra que o uso combinado de águas doce e solobras adotado no Experimento II pode representar menor restrição à absorção de água pelas plantas, o que se constitui uma vantagem comparativa ao Experimento I, já que diversas pesquisas têm reportado o efeito da salinidade sobre a diminuição da transpiração e, por conseguinte, da produtividade das culturas (Viana et al., 2004; Cavalcanti et al., 2005; Correia et al., 2005; Ruiz-Sánchez et al., 2000). A diminuição da área foliar representa uma demanda menor de água e é considerada um mecanismo de adaptação das plantas às condições salinas, uma vez que quanto maior a salinidade do meio maior também é a dificuldade para absorção de água; esta é uma assertiva fisiológica para todo tipo de cultivo, inclusive o hidropônico, no qual a abundância de água não impede a dificuldade em sua absorção na condição salina.

De fato, o aumento da salinidade da água resultou em perdas produtivas no presente estudo, mas com distinções entre os experimentos. Conforme análise de regressão, todas as variáveis analisadas, à exceção do número de folhas, so-

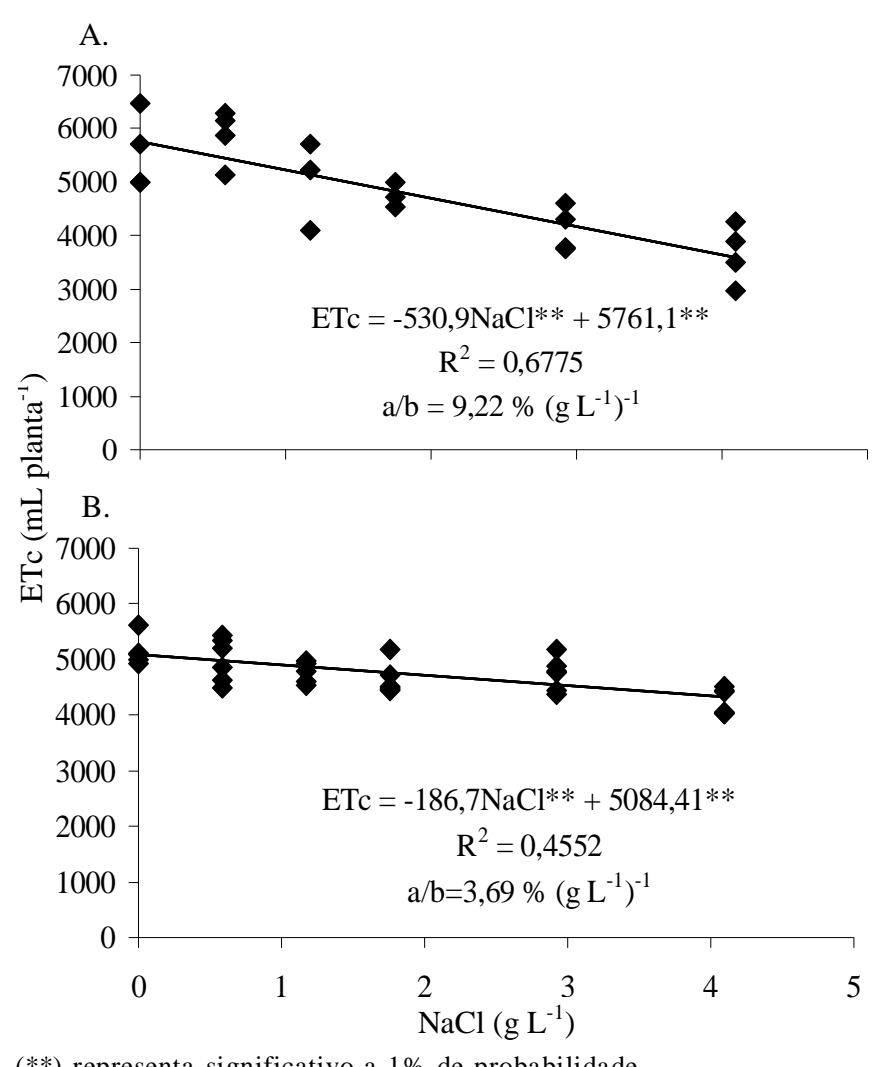

(**) representa significativo a $1 \%$ de probabilidade

Figura 4. Consumo de água (ETc)em função da salinidade da água nos Experimentos I (2 a 25 DAT) (A) e II (5 a 25 DAT) (B)

freram redução linear com o aumento da concentração de $\mathrm{NaCl}$ nas águas salobras. Os valores da razão a/b entre os coeficientes angular (a) e linear (b) das equações de primeiro grau ajustadas foram maiores no Experimento I que no Experimento II, para todas as variáveis analisadas, significando que, para cada aumento unitário na concentração de $\mathrm{NaCl}\left(1 \mathrm{~g} \mathrm{~L}^{-1}\right)$, as reduções percentuais registradas no Experimento I foram mais acentuadas.

A ausência de efeito da salinidade da água sobre o número de folhas em ambos os experimentos do presente estudo está de acordo com os resultados de Andriolo et al. (2005), que cultivaram alface crespa 'Vera' com diferentes concentrações de nutrientes $\left(0,8\right.$ a 4,72 $\left.\mathrm{dS} \mathrm{m}^{-1}\right)$ na solução nutritiva, em hidroponia.

As reduções lineares das massas de matéria fresca da parte aérea da alface (Figura 5A e 5B) seguiram a mesma ordem de valores percentuais encontrados para o consumo hídrico entre os experimentos. No Experimento I, a redução foi de 10,9\% e no Experimento II foi de 3,91\% para cada $\mathrm{g} \mathrm{L}^{-1}$ de $\mathrm{NaCl}$ acrescida na água; já em relação à massa de matéria seca da parte aérea, a redução mensurada no Experimento I foi de 7,57\% (g $\left.\mathrm{L}^{-1}\right)^{-1}$, enquanto não houve significância nas diferenças registradas no Experimento II para esta variável (Figura 6A e 7B).

$\mathrm{O}$ efeito significativo da salinidade da água sobre a MFPA, em contraposição à falta de efeito sobre o número de folhas, indica que nas condições salinas testadas, a alface 'Verônica' reduziu sua massa foliar mediante a redução do tamanho das folhas e não por deixar de produzi-las. 


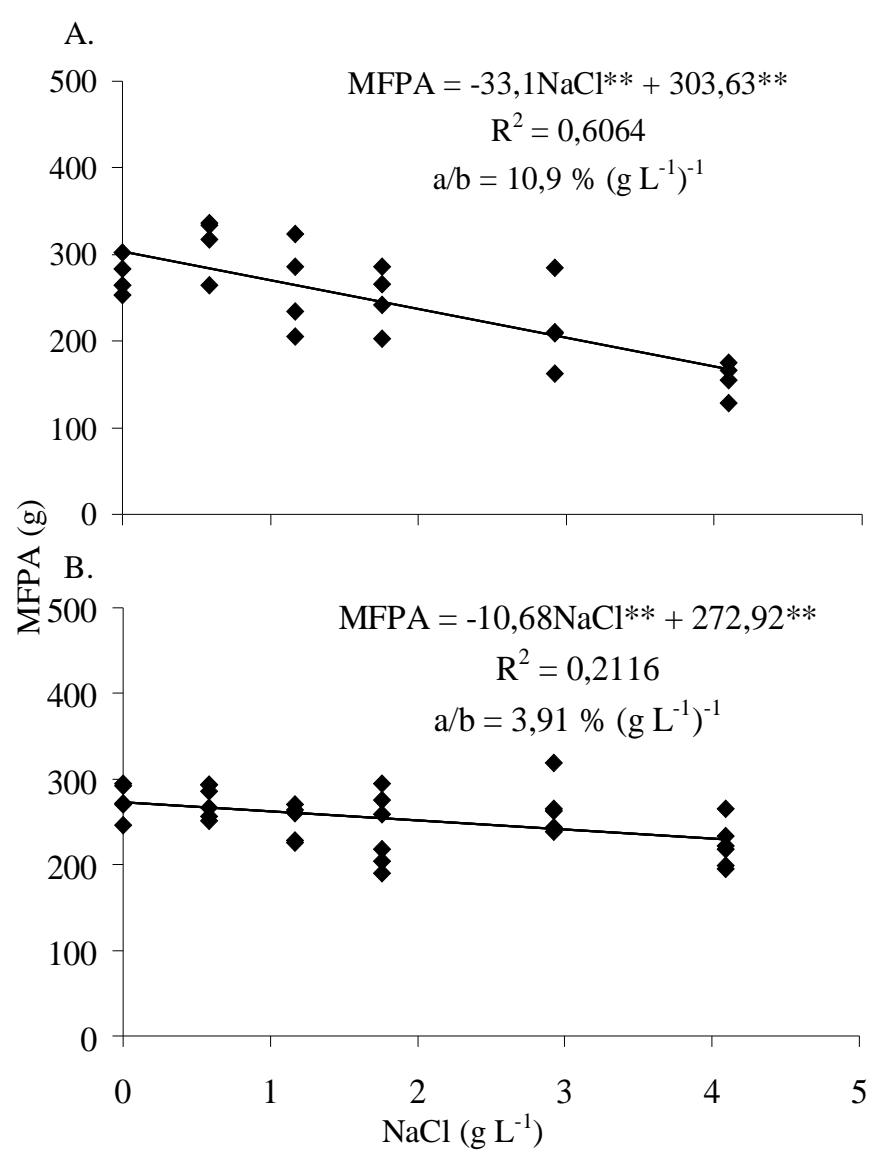

(**) representa significativo a $1 \%$ de probabilidade

Figura 5. Massa de matéria fresca da parte aérea da alface em função da salinidade da água nos Experimentos I (A) e II (B)

Essas baixas reduções percentuais encontradas no Experimento II representam efeito mais moderado das águas salobras sobre a produção da alface cv. Verônica, quando são utilizadas, em combinação com água doce, apenas na reposição da ETc. Para a produtividade comercial, considerada a massa de matéria fresca da parte aérea, calculou-se uma perda de $19,3 \%$ quando se utilizou a água mais salobra $\left(4,09 \mathrm{~g} \mathrm{~L}^{-}\right.$ ${ }^{1} \mathrm{de} \mathrm{NaCl} ; 7,29 \mathrm{dS} \mathrm{m}^{-1}$ ), em relação à testemunha (Figura 5B). Em referência à produção de massa de matéria seca, a perda pelo uso dessa água foi de apenas $7 \%$ (Figura 6B), resultados que demonstram grande possibilidade de aplicação desse tipo de combinação de águas para a produção de alface em hidroponia.

Para produtores que têm disponibilidade de água salobra e restrita disponibilidade de água doce, resultados como o do presente trabalho, em hidroponia NFT, podem indicar a possibilidade de incremento da produção agrícola mediante a exploração da água salobra, agregando a vantagem do maior controle ambiental e a preservação da água doce para outros fins.

$\mathrm{O}$ uso combinado de águas moderadamente salobras (CEa $<3,5 \mathrm{dS} \mathrm{m}^{-1}$ ) com água doce permitiu a obtenção de produtividades relativas (à testemunha) superiores a $80 \%$ quando utilizadas apenas no preparo da solução nutritiva (Experimento I, Figura 5A). Quando utilizadas apenas na reposição do volume consumido, águas ainda mais salobras $\left(\mathrm{CEa}<7,5 \mathrm{dS} \mathrm{m}^{-}\right.$ $\left.{ }^{1}\right)$ permitiram produtividades relativas acima desse mesmo patamar (Experimento II, Figura 5B). A superioridade deste último tipo de emprego de águas salobras precisa ser comprovada estatisticamente em uma investigação envolvendo ambos os tipos nas mesmas condições climáticas de cultivo, pois o efeito dessas condições sobre o consumo hídrico deve ser evitado.

Ainda que no presente trabalho os Experimentos I e II tenham sido conduzidos sob condições climáticas distintas, uma atenuante favorável à comparação de seus resultados diz respeito ao fato da pouca variação do volume de água consumido por planta para o tratamento controle (T0 e W0). Teoricamente, o volume consumido pelas plantas-controle deveria ser semelhante nos dois tipos de experimento em condições climáticas semelhantes.

Para o Experimento II, o consumo hídrico acumulado foi de 5,150 L por planta (5 a 25 DAT), enquanto para o Experimento I foi de 5,543 L por planta (2 a 25 DAT). Para o Experimento II, o consumo de água é importante porque dele depende a salinização do meio, ou seja, a resposta da planta à salinidade fica muito dependente das condições climáticas que ditam o consumo nesse tipo de experimento. Para o outro tipo de experimento, o potencial osmótico é mais constante, independendo menos do consumo.

Em relação à produção das plantas-controle, cujos tratamentos equivalentes nos Experimento I e II são, respectivamente, T0 e W0, não houve diferença absoluta. Em ambos os casos foram produzidos aproximadamente $275 \mathrm{~g}$ de massa de

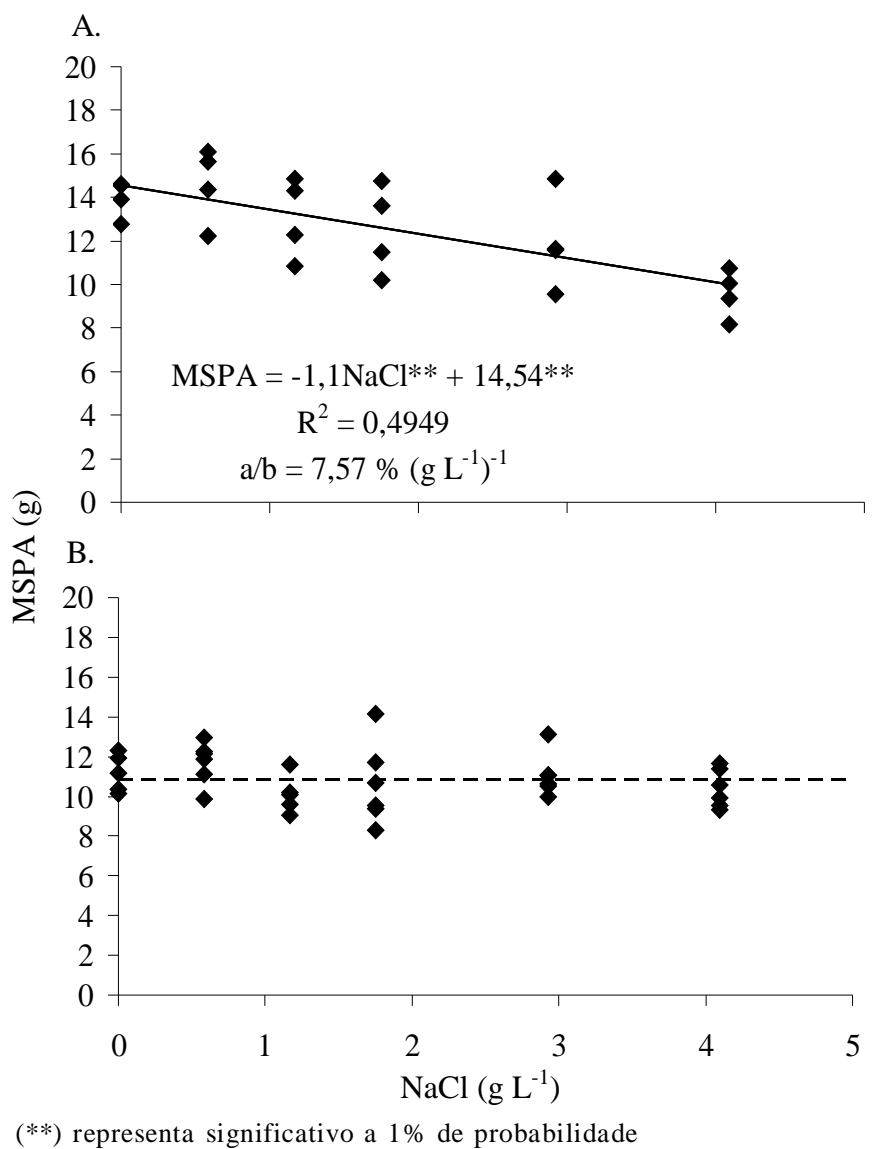

Figura 6. Efeito da salinidade da água sobre a massa de matéria seca da parte aérea da alface nos Experimentos I (A) e II (B) 
matéria fresca da parte aérea da alface crespa 'Verônica' colhida aos 25 DAT. Por outro lado, parece ter ocorrido uma concentração maior de matéria seca nas plantas-controle do Experimento I, para o qual se registrou uma massa de 13,96 g (Figura 6A), enquanto 11,19 g foram registradas no Experimento II (Figura 6B). Plantas da mesma cultivar produziram 259,71 g de MFPA em 24 DAT no estudo de Paulus (2008) e 278,8 g em 30 DAT no estudo de Casaroli et al. (2003), resultados esses que exemplificam como as plantas controle do presente estudo produziram dentro do esperado para a cultivar 'Verônica'.

Em ambos os experimentos do presente estudo não foram observados sintomas de toxidez ou deficiência mineral que pudessem ser atribuídos à salinidade e que levassem ao comprometimento da qualidade do produto. Nos maiores níveis de salinidade, as plantas de alface apresentaram coloração verde mais escuro, além de aspecto mais coriáceo. Esses sintomas foram mais evidentes no Experimento I que no Experimento II; portanto, o peso dessas características sensoriais, incluindo o sabor, deveria ser ponderado no valor comercial da produção. Na Figura 7A se tem o exemplo do aspecto visual de plantas de alface cv. Verônica quando submetida ao tratamento controle (T0) e ao tratamento mais salino (T7) no

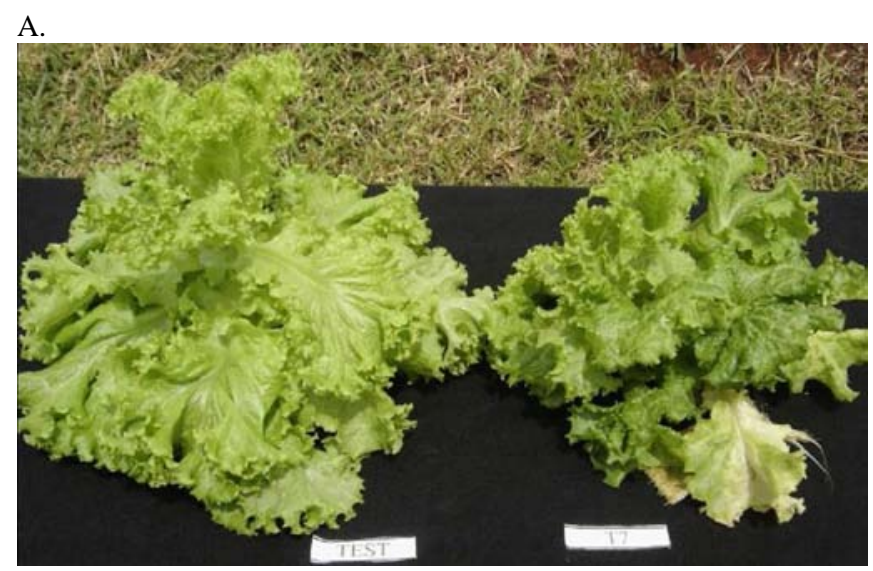

B.

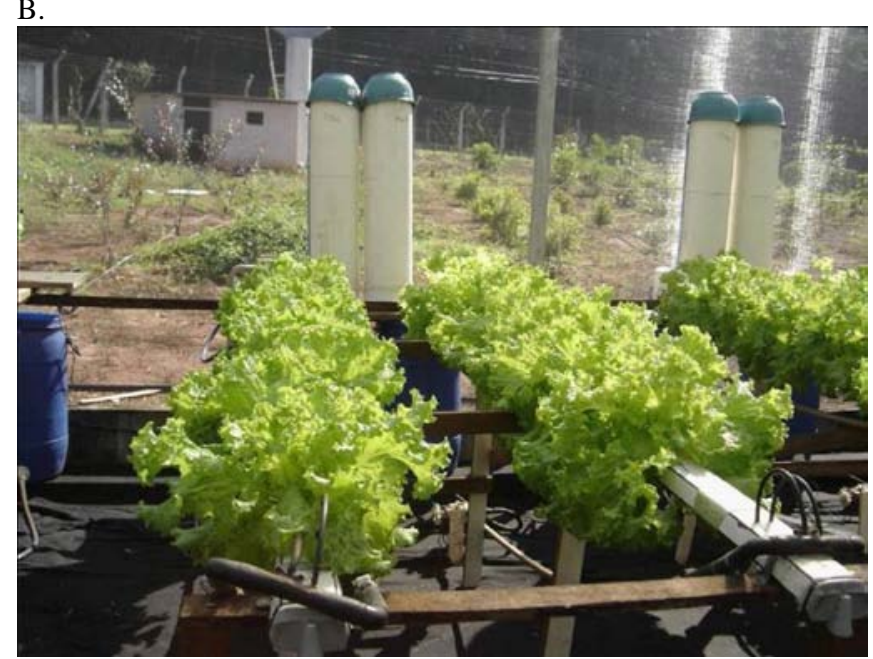

Figura 7. Aspecto geral da alface produzida com solução nutritiva não salinizada (esquerda) e sal inizada com 77 (à direita) ao final do Experimento I (A) e aspecto geral da alface cv. Verônica irrigada com a água W 7 (à esquerda) e irrigada com água não salobra (à direita) no Experimento II (B)

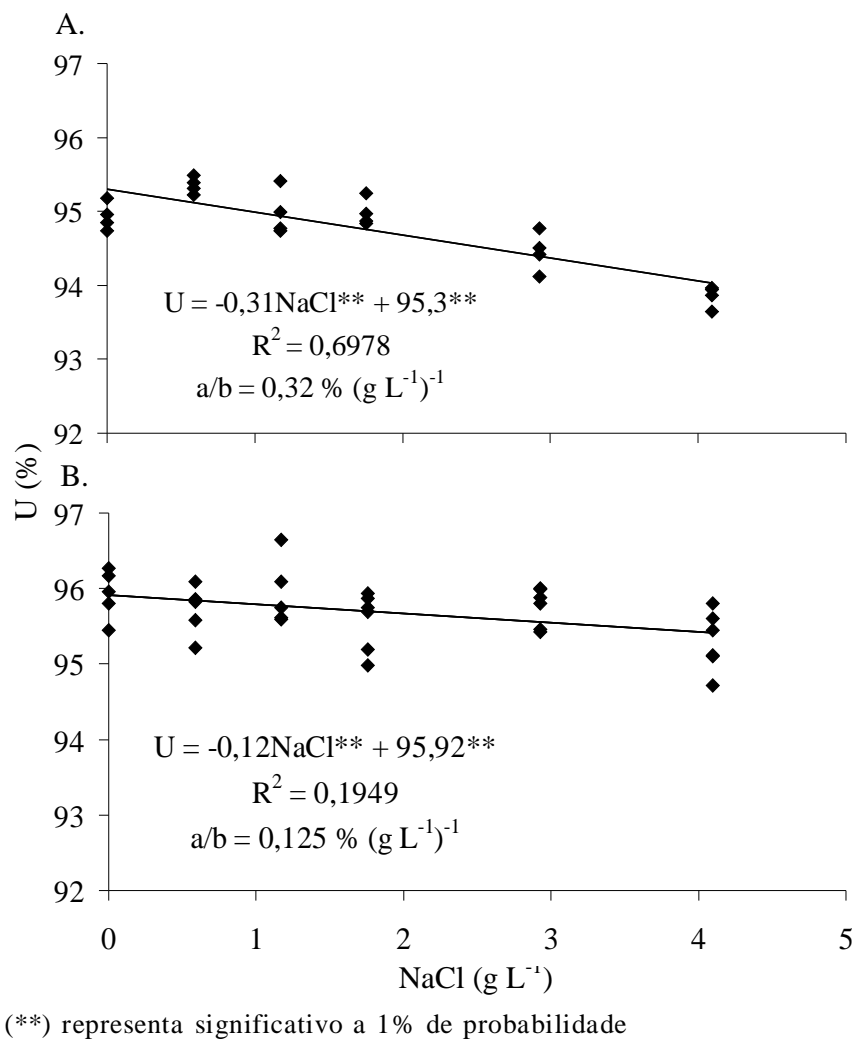

Figura 8. Teor de água na parte aérea (U) em função da salinidade da água nos Experimentos I (A) e II (B)

Experimento I. Destaca-se a inobservância de injúrias foliares como manchas e queimaduras, mas o menor porte das plantas sob o efeito da maior salinidade. No Experimento II (Figura 7B), por outro lado, notou-se semelhança na magnitude de crescimento da alface cv. Verônica produzida mediante o emprego da água mais salobra (W7), em relação ao controle (W0).

As mudanças na tonalidade do verde foliar e o aspecto coriáceo das plantas submetidas às maiores salinidades da água também foram verificadas por outros autores (Paulus, 2008; Shannon et al., 1983; Tesi et al., 2003). Em análise de intenção de compras para plantas de alface produzidas com águas salobras em hidroponia, com os mesmos sintomas anteriormente descritos, Paulus (2008) não registrou efeito negativo da salinidade.

No Experimento I, a massa de matéria fresca da parte aérea foi variável em função da redução do acúmulo de matéria seca e do teor de água. Por outro lado, no Experimento II, que trata da salinização gradual, a massa de matéria fresca (Figura 5B) pode estar mais influenciada pelo teor de água que pelo acúmulo de matéria seca (Figura 6B), o que é concordante com o aspecto coriáceo menos intenso que o do Experimento I, visto que, à medida em que se aumenta a salinidade da água de reposição, o teor de água na parte aérea diminui (Figura 8B), mas a massa de matéria seca não (Figura 6B).

\section{CONCLUSÕES}

1. Em ambos os tipos de combinação de águas doce e salobras não foram detectados sintomas deletérios de toxidez ou de deficiência mineral que pudessem ser atribuídos à 
salinidade. Toda a massa de matéria fresca pôde ser avaliada como produção comercial.

2. Quando as águas salobras foram usadas apenas no preparo da solução nutritiva, observou-se nanismo das plantas e maior intensidade na coloração verde-escuro e no aspecto coriáceo das folhas de alface submetida aos maiores níveis de salinidade. Quando as águas salobras foram usadas apenas na reposição da evapotranspiração, o porte das plantas foi visualmente semelhante ao das plantas-controle.

3. A salinização gradativa não foi tão prejudicial para a absorção de água quanto a salinidade constante da solução nutritiva.

4. Levando em conta o curto ciclo da alface, quando houver interesse em se combinar águas doce e salobra, poderá ser mais produtivo usar a água doce no preparo da solução nutritiva e empregar a água salobra para a reposição do volume consumido.

\section{AGRADECIMENTOS}

Às empresas METALCORTE/EBERLE (Leandra Sartori), HIDROGOOD (Carlos Banho e Carlos Orlandi), TIGRE (Olacir Martins Luciano) e HANNA INSTRUMENTS (Marcio Siqueira), pelo fornecimento de equipamentos e boa vontade em auxiliar a pesquisa; à Coordenadoria de Aperfeiçoamento de Pessoal de Nível Superior (CAPES) pela concessão da bolsa de estudo e apoio, mediante seu programa PROAP.

\section{LITERATURA CITADA}

Amorim, D. M. B.; Notaro, I. A.; Furtado D. A.; Gheyi H. R.; Baracuhy, J. G. de V. Avaliação de diferentes níveis de salinidade da água utilizada na produção de forragem hidropônica de milho. Revista Brasileira de Engenharia Agrícola e Ambiental, v.9, p.339-342, 2005.

Andrade, E. M.; D’Almeida, D. M. B. A.; Meireles, A. C. M.; Lemos Filho, L. C. A.; Arruda, F. E. R. Evolução da concentração iônica da solução do solo em áreas irrigadas na Chapada do Apodi, Ceará. Revista Ciência Agronômica, v.35, n.1, p.9-16, 2004.

Andrade Júnior, A. S.; Silva, E. F. F.; Bastos, E. A.; Melo, F. B.; Leal, C. M. Uso e qualidade da água subterrânea para irrigação no semi-árido piauiense. Revista Brasileira de Engenharia Agrícola e Ambiental, v.10, n.4, p.873-880, 2006.

Andriolo, J. L.; Luz, G. L.; Witter, M. H.; Godoi, R. S.; Barros, G. T.; Bortolotto, O. C. Growth and yield of lettuce plants under salinity. Horticultura Brasileira, v.23, n.4, p.931-934, 2005.

Ayers, R. S.; Westcot, D. W. A qualidade da água na agricultura. 2.ed. Campina Grande: UFPB, 1999. 153p. Estudos FAO. Irrigação e Drenagem, 29 revisado

Barros, M. F. C.; Fontes, M. P. F.; Alvarez V.; V. H.; Ruiz, H. A. Recuperação de solos afetados por sais pela aplicação de gesso de jazida e calcário no Nordeste do Brasil. Revista Brasileira de Engenharia Agrícola e Ambiental, v.8, n.1, p.59-64, 2004.
Casaroli, D.; Fagan, E. B.; Santos, O. S.; Bonnecarrère, R. A. G.; Nogueira Filho, H. Desempenho de onze cultivares de alface em duas formas diferentes de canais de cultivo, no sistema hidropônico. Revista da Faculdade de Zootecnia, Veterinária e Agronomia, v.10, p.114-123, 2003.

Cavalcanti, M. L. F.; Fernandes, P. D.; Gheyi, H. R.; Barros Júnior, G.; Soares, F. A. L.; Siqueira, E. C. Índices ecofisiológicos da mamoneira sob estresse salino. Revista Brasileira de Engenharia Agrícola e Ambiental, v.9, p.66-70, 2005.

Correia, K. G.; Fernandes, P. D.; Gheyi, H. R.; Gurgel, M. T.; Rodrigues, L. N. Crescimento do amendoinzeiro irrigado com águas salinas. Revista Brasileira de Engenharia Agrícola e Ambiental, v.9, p.81-85, 2005.

Costa, A. M. B.; Melo, J. G. E.; Silva, F. M. Aspectos da salinização das águas do aqüífero cristalino no estado do Rio Grande do Norte, Nordeste do Brasil. Águas Subterrâneas, v.20, n.1, p.67-82, 2006.

Eloi, W. M.; Duarte, S. N.; Soares, T. M. Níveis de salinidade e manejo da fertirrigação sobre características do tomateiro cultivado em ambiente protegido. Revista Brasileira de Ciências Agrárias, v.2, p.83-89, 2007.

Furlani, P. R.; Silveira, L. C. P.; Bolonhezi, D.; Faquin, V. Cultivo hidropônico de plantas. Campinas: IAC, 1999. 52p. Boletim Técnico, 180.

Lopes, J. F. B.; Andrade, E. M.; Chaves, L. C. G. Impacto da irrigação sobre os solos de perímetros irrigados na Bacia do Acaraú, Ceará, Brasil. Engenharia Agrícola, v.28, n.1, p.34-43, 2008 .

Medeiros, J. F. de; Lisboa, R. A.; Oliveira, M.; Silva Júnior, M. J.; Alves, L. P. Caracterização das águas subterrâneas usadas para irrigação na área produtora de melão da Chapada do Apodi. Revista Brasileira de Engenharia Agrícola e Ambiental, v.7, n.3, p.469-472, 2003.

Medeiros, P. R. F.; Duarte, S. N.; Dias, C. T. S. Tolerância da cultura do pepino a salinidade em ambiente protegido. Revista Brasileira de Engenharia Agrícola e Ambiental, v.13, n.4, p.406-410, 2009.

Nunes Filho, J.; Sousa, R.; Sá, V. A. L.; Lima, B. P. Relações entre a concentração de águas subterrâneas e superficiais, visando à irrigação, no sertão de Pernambuco. Revista Brasileira de Engenharia Agrícola e Ambiental, v.4, n.2, p.189-93, 2000.

Paulus, D. Produção, qualidade e parâmetros fisiológicos e bioquímicos de alface sob hidroponia com águas salinas. Piracicaba: ESALQ, 2008. 105p. Tese Doutorado

Rodrigues, L. R. F. Técnicas de cultivo hidropônico e de controle ambiental no manejo de pragas, doenças e nutrição vegetal em ambiente protegido. Jaboticabal: FUNEP, 2002. 762p.

Ruiz-Sánchez, M. C.; Domingo, R; Torrecillas, A.; Pérez-Pastor, A. Water stress preconditioning to improve drought resistance in young apricot plants, Plant Science, v.56, n.2, p.245-251, 2000.

Santos, A. N. Rendimento e avaliação nutricional do cultivo hidropônico de alface em sistema NFT no semiárido brasileiro utilizando águas salobras. Recife: UFRPE, 2009. 133p. Dissertação Mestrado

Santos, S. R.; Pereira, G. M. Comportamento da alface tipo americana sob diferentes tensões da água no solo, em ambiente protegido. Engenharia Agrícola, v.24, n.3, p.569-577, 2004.

Shannon, M. C.; Mccreigth, J. D.; Draper, J. H. Screening test for salt tolerance in lettuce. Journal of the American Society for Horticulture Science, v.108, n.2, p.225-230, 1983. 
Soares, T. M. ; Duarte, S. N., Silva, E. F. F., Melo, R. F., Jorge, C.A., Oliveira, A. S. Experimental structure for evaluation of saline water use in lettuce hydroponic production. Irriga, v.14, n.1, p.102-114, 2009.

Soares, T. M.; Silva, E. F. F.; Duarte, S. N.; Melo, R. F.; Jorge, C. A.; Bonfim-Silva, E. M. Produção de alface utilizando águas salinas em sistema hidropônico. Irriga, v.12, n.2, p.235-248, 2007.

Tesi, R.; Lenzi, A.; Lombardi, P. Effect of salinity and oxygen level on lettuce grown in a floating system. Acta Horticulturae, v.609, p.383-387, 2003.
Viana, S. B. A.; Fernandes, P. D.; Gheyi, H. R.; Soares, F. A. L.; Carneiro, P. T. Índices morfofisiológicos e de produção de alface sob estresse salino. Revista Brasileira de Engenharia Agrícola e Ambiental, v.8, n.1, p.23-30, 2004.

Zanella, F.; Lima, A. L. S; Silva Júnior, F. F.; Maciel, S. P. A. Crescimento de alface hidropônica sob diferentes intervalos de irrigação. Ciência e Agrotecnologia, v.32, n.2, p.366-370, 2008.

Zoby, J. L. G.; Oliveira, F. R. Panorama da qualidade das águas subterrâneas no Brasil. Brasília: ANA, 2005. 73p. 